\title{
New Series of BPL Inhibitors To Probe the Ribose-Binding Pocket of Staphylococcus aureus Biotin Protein Ligase
}

\author{
Jiage Feng, ${ }^{\dagger, \$}$ Ashleigh S. Paparella, ${ }^{\S}$ William Tieu, ${ }^{\dagger, \|}$ David Heim, ${ }^{\S}$ Sarah Clark, ${ }^{\dagger}$ Andrew Hayes, ${ }^{\S}$
} Grant W. Booker, ${ }^{\S}$ Steven W. Polyak, ${ }^{\S}$ and Andrew D. Abell $*^{\dagger} \dagger$,

${ }^{\dagger}$ Department of Chemistry, ${ }^{\S}$ Department of Molecular and Cellular Biology, and ${ }^{\ddagger}$ Centre for Nanoscale BioPhotonics (CNBP), University of Adelaide, Adelaide, South Australia 5005, Australia

\section{Supporting Information}

ABSTRACT: Replacing the labile adenosinyl-substituted phosphoanhydride of biotinyl-5' AMP with a N1-benzyl substituted 1,2,3-triazole gave a new truncated series of inhibitors of Staphylococcus aureus biotin protein ligase ( $\mathrm{SaBPL}$ ). The benzyl group presents to the ribose-binding pocket of $\mathrm{SaBPL}$ based on in silico docking. Halogenated benzyl derivatives $(12 t, 12 u, 12 w$, and $12 x)$ proved to be the most potent inhibitors of SaBPL. These derivatives inhibited the growth of $S$. aureus ATCC49775 and displayed low cytotoxicity against HepG2 cells.

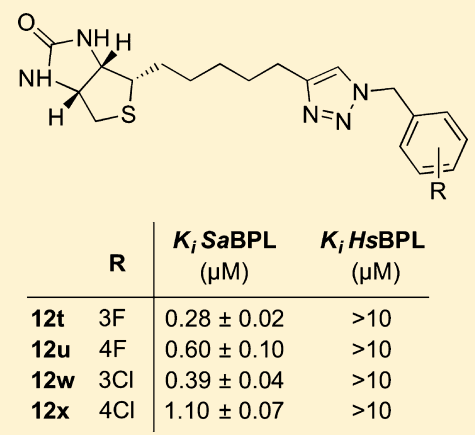

KEYWORDS: Enzyme inhibitors, antibiotics, biotin protein ligase, Staphylococcus aureus

B iotin protein ligase (BPL) catalyzes the reaction of biotin 1 and ATP 2 to give biotinyl-5'-AMP 3, which then biotinylates and activates essential metabolic enzymes required for fatty acid biosynthesis and gluconeogenesis, specifically acetyl CoA carboxylase and pyruvate carboxylase (Figure 1$){ }^{1-5}$

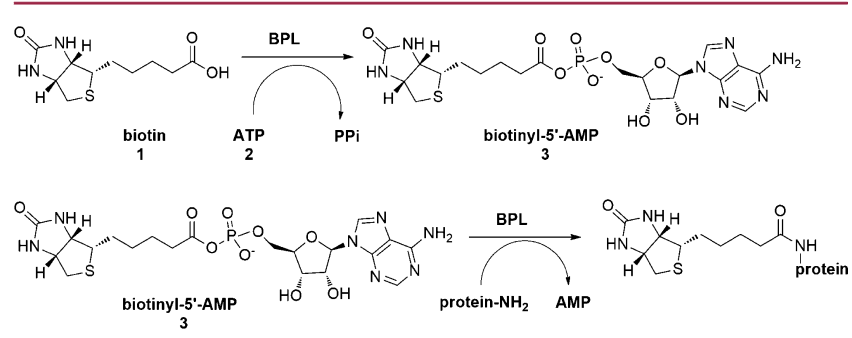

Figure 1. General mechanism of BPL catalyzed biotinylation.

A number of analogues of biotinyl-5'-AMP have recently been reported as inhibitors of BPL as shown in Figure 2. Some of these compounds have potential as antibacterial agents by inhibiting BPL from clinically important pathogens such as Staphylococcus aureus, ${ }^{6}$ Escherichia coli, ${ }^{7,8}$ and Mycobacterium tuberculosis. ${ }^{9,10}$ A range of bioisosteres have been investigated as replacements for the labile phosphoanhydride of biotinyl- 5 ' AMP 3, including phosphodiester $4,{ }^{11,12}$ hydroxyphosphonate $\mathbf{5}^{13}$ ketophosphonate $\mathbf{6},{ }^{13}$ acylsulfamate $7,{ }^{11}$ and sulphonmyl amide $\mathbf{8}^{10}$ (Figure 2). We have also reported biotin triazoles (e.g., 9-11) as a novel class of BPL inhibitor that selectively targets BPL from the clinically important bacterial pathogen Staphylococcus aureus over the human homologue. $3,14,15$

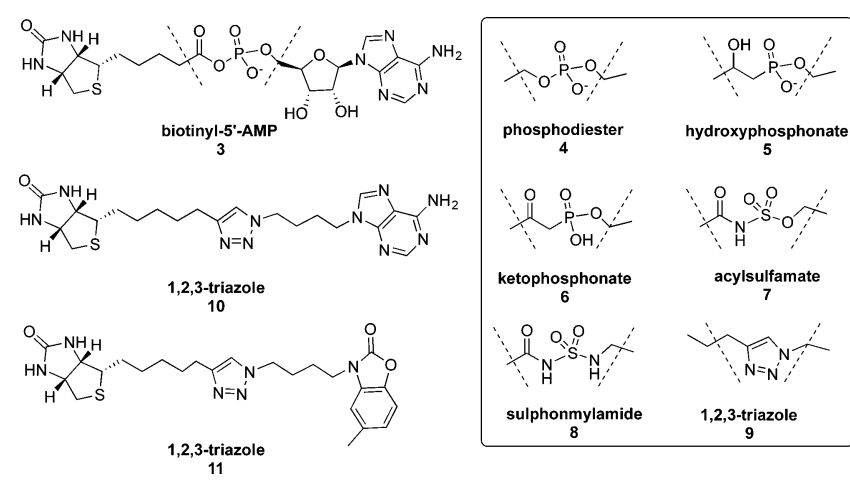

Figure 2. Reported BPL inhibitors, with isosteric replacements for the phosphoanhydride of biotinyl-5'-AMP 3 shown in the box.

Without exception, all isostere-based BPL inhibitors reported to date contain a biotin and an adenine group, or analogue thereof, as discussed above and as shown in Figure 2. These two groups occupy well-defined binding pockets in the enzyme as per biotinyl-5'-AMP 3, as supported by X-ray crystallographic and mutagenesis studies. 3,16 The ribose group of the triazole series can be removed as in 10, and the adenine can be modified as in 11, which has improved stability and $>1000$-fold specificity for the BPL from $S$. aureus over the human homologue. ${ }^{3}$ We now report the first examples of truncated 1,2,3-triazole-based BPL inhibitors with a 1-benzyl substituent

Received: June 26, 2016

Accepted: October 10, 2016

Published: October 10, 2016 
designed to interact with the ribose binding pocket of $S$. aureus $\mathrm{BPL}(\mathrm{S} a \mathrm{BPL})$, see $\mathbf{1 2 a}-\mathbf{y}$, Figure 3. These derivatives are the

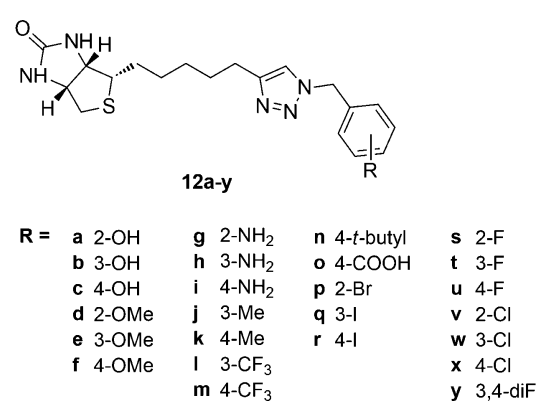

Figure 3. Benzyl-substituted 1,2,3-triazole analogues.

first examples of isostere-based BPL inhibitors lacking an appended adenine or analogue thereof and the associated tether as discussed above. The ribose-binding pocket is composed of amino acids that provide potential hydrogen bonding sites, specifically through the side chains of K187, R122, R125, and R227 as well as the backbone peptide atoms from H126 and S128 (Figure 4a). This series of inhibitors provides an important starting point for further optimization and antibiotic development.

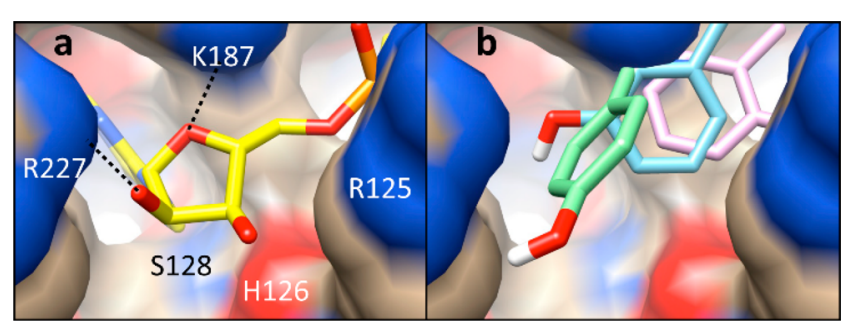

Figure 4. (a) X-ray structure of the SaBPL active site with biotinyl-5'AMP 3 (yellow) bound PDB ID 3RIR. ${ }^{10}$ Amino acids that encompass the ribose-binding pocket are shown. Dashed lines represent hydrogen bonds. (b) In silico docking poses for biotin triazole analogues 12a, 12b, and 12c containing a hydroxyl group at C2- (pink), C3- (blue), and C4- (green), respectively.

In silico docking experiments were carried out in order to explore possible binding modes by which this series of benzyl analogues might occupy the active site of $\mathrm{SaBPL}$. Flexible ligand docking was carried out using AutoDockTools (version 1.5.6). The docking protocol was first validated by removing compound 11 from its cocrystal structure with S. aureus BPL (PDB 3V7S) and then redocking. This occurred with a high degree of commonality as revealed by superimposition of the docked and crystallized ligands in the active site. We next docked benzylated triazoles 12a-c (Figure 3) into SaBPL. Each of these structures contains a single hydroxyl substituent on the benzyl ring capable of forming a hydrogen bond as per the diol in the ribose of biotinyl-5'-AMP 3. Gratifyingly, the top ranking poses of all three analogues placed the hydroxyl group in the site occupied by the ribose diol of 3 (Figure 4a). Rotation around the alkyl linker connecting the triazole and benzyl moieties produced subtly different poses with regards to the ribose-binding site (Figure 4b). These binding modes minimized steric clashes with the protein and facilitated hydrogen bonding between the alcohol group and R122 for 12a and R227 for 12b and 12c. This data reflects an apparent openness of the solvent exposed pocket and suggests that this site can accommodate a variety of functional groups as exemplified in the extended series depicted in Figure 3. Synthesis and biological testing of this series provides an opportunity to probe potential interaction with the ribose pocket.

The synthesis of the 1,2,3-triazoles $12 \mathbf{a}-\mathbf{y}$ was carried out as summarized in Scheme 1. The key benzyl azides $14 \mathbf{a}-\mathbf{y}$ were
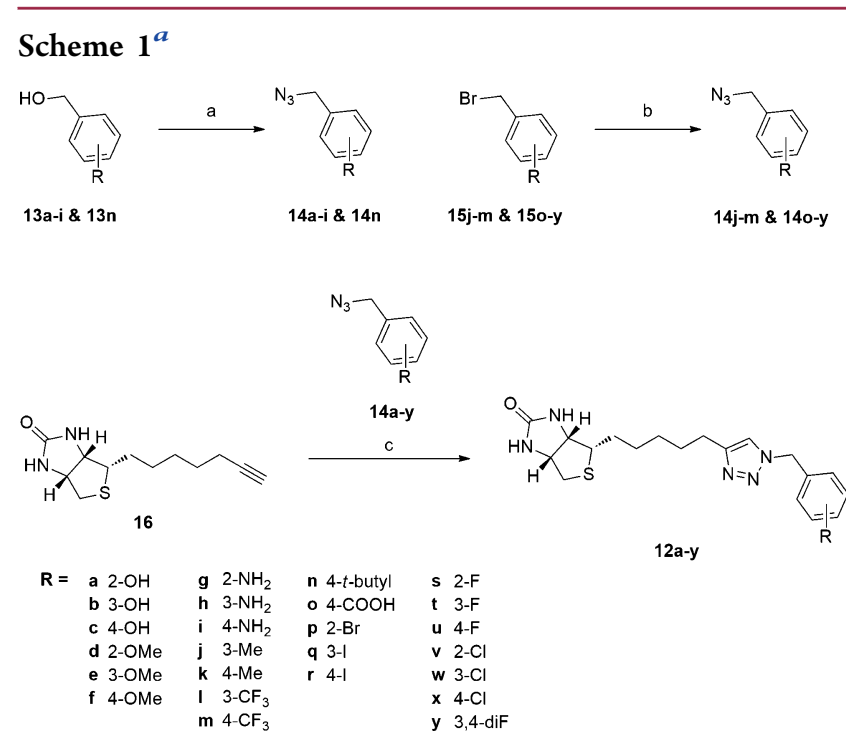

${ }^{a}$ Conditions and reagents: (a) (i) $\mathrm{PPh}_{3}, \mathrm{CCl}_{4}, \mathrm{DMF}$; (ii) $\mathrm{NaN}_{3}, \mathrm{DMF}$, rt; (b) $\mathrm{NaN}_{3}, \mathrm{DMF}, \mathrm{rt}$; (c) $\mathrm{Cu}_{2} \mathrm{SO}_{4}$ ascorbate, DMSO $/ \mathrm{H}_{2} \mathrm{O}, \mathrm{rt}, 12 \mathrm{~h}$ (give 12a-y $(18 \%-55 \%)$ ).

prepared from commercially available benzyl alcohols (13a-i and $13 n)$ and bromides $(15 j-m$ and $150-y)$. Specifically, commercially available benzyl alcohols $13 a-i$ and $13 n$ were converted directly ${ }^{17}$ into the corresponding azides $14 a-i$ and $14 n$ on reaction with triphenylphosphine, in the presence of carbon tetrachloride and sodium azide at ambient temperature. The second series of benzyl azides $(\mathbf{1 4} \mathbf{j}-\mathbf{m}$ and $\mathbf{1 4 0}-\mathbf{y})$ was prepared from commercially available benzyl bromides $15 \mathbf{j}-\mathbf{m}$ and 15o-y on reaction with sodium azide in DMF as shown. Huisgen cycloaddition of biotin alkyne $16^{18}$ with each of the benzyl azides $14 a-y$, in the presence of copper sulfate and sodium ascorbate, ${ }^{3}$ then gave the desired 1,2,3-triazole 12a-y as shown.

The activity profiles of 1,2,3-triazoles $12 \mathbf{a}-\mathbf{y}$ were determined using established biochemical and microbiological assay protocols. ${ }^{3,19}$ Compounds displaying inhibitory activity against $\mathrm{SaBPL}$ and cytotoxic activity against bacteria, but not mammalian cells, are considered important candidates for further antibiotic development. The in vitro potency and selectivity profiles of the 1,2,3-triazoles $12 \mathbf{a}-\mathbf{y}$ were measured using recombinant BPLs from S. aureus and Homo sapiens. Here the enzymatic incorporation of radiolabeled biotin onto an acceptor protein was measured in the presence of varying concentrations of each compound with the results shown in Tables 1 and 2. Previous enzymology and X-ray crystallography studies have demonstrated that the biotin triazoles are competitive inhibitors against biotin,,$^{3,15,16}$ and as such, inhibitory constants $\left(K_{\mathrm{i}}\right)$ were calculated from $\mathrm{IC}_{50}$ values using the known $K_{\mathrm{M}}$ for biotin as previously described. ${ }^{20}$ The antibacterial activity of the compounds was also determined using S. aureus strain ATCC $49775 .{ }^{18}$ Growth of the bacteria 20 $\mathrm{h}$ post-treatment was measured spectrophotometrically at 600 
Table 1. In Vitro Biotinylation and Antibacterial Assay Results for Benzyl Triazole Series 1

\begin{tabular}{|c|c|c|c|c|}
\hline ID & $\mathrm{R}$ & $\begin{array}{c}K_{\mathrm{i}} \underset{(\mu \mathrm{BPPL}}{(\mu \mathrm{M})} \\
\end{array}$ & $K_{\mathrm{i}} \underset{(\mu \mathrm{M})}{\operatorname{human}} \mathrm{BPL}$ & $\begin{array}{c}\text { anti-S. aureus } \\
\text { activity }^{a}\end{array}$ \\
\hline $12 a$ & $2-\mathrm{OH}$ & $>10$ & $>16$ & - \\
\hline $12 b$ & $3-\mathrm{OH}$ & $>10$ & $>16$ & - \\
\hline $12 c$ & $4-\mathrm{OH}$ & $1.59 \pm 0.08$ & $>16$ & - \\
\hline $12 d$ & 2-OMe & $0.53 \pm 0.05$ & $>16$ & - \\
\hline $12 \mathrm{e}$ & 3-OMe & $1.17 \pm 0.1$ & $>16$ & - \\
\hline $12 \mathrm{f}$ & 4-OMe & $>10$ & $>16$ & - \\
\hline $12 \mathrm{~g}$ & 2- $\mathrm{NH}_{2}$ & $1.48 \pm 0.14$ & $>16$ & + \\
\hline $12 \mathrm{~h}$ & $3-\mathrm{NH}_{2}$ & $>10$ & $>16$ & - \\
\hline $12 \mathrm{i}$ & $4-\mathrm{NH}_{2}$ & $>10$ & $>16$ & - \\
\hline $12 \mathrm{j}$ & 3-Me & $0.71 \pm 0.04$ & $>16$ & + \\
\hline $12 \mathrm{k}$ & 4-Me & $>10$ & $>16$ & - \\
\hline 121 & $3-\mathrm{CF}_{3}$ & $>10$ & $>16$ & - \\
\hline $12 \mathrm{~m}$ & $4-\mathrm{CF}_{3}$ & $>10$ & $>16$ & - \\
\hline $12 n$ & 4- $t \mathrm{Bu}$ & $1.22 \pm 0.07$ & $>16$ & + \\
\hline $12 o$ & 4-COOH & $0.67 \pm 0.06$ & $>16$ & - \\
\hline $12 p$ & $2-\mathrm{Br}$ & $0.96 \pm 0.13$ & $>16$ & + \\
\hline $12 q$ & 3-I & $>10$ & $>16$ & - \\
\hline $12 r$ & 4-I & $0.56 \pm 0.06$ & $>16$ & + \\
\hline
\end{tabular}

$a_{+}$, Optical density of the culture reduced by $>40 \%$ of nontreated controls. -, compound did not inhibit bacterial growth.

Table 2. In Vitro Biotinylation and Antibacterial Assay Results for Benzyl Triazole Series 2

\begin{tabular}{|c|c|c|c|c|c|}
\hline ID & $\mathrm{R}$ & $\begin{array}{c}K_{\mathrm{i}} \text { SaBPL } \\
(\mu \mathrm{M})\end{array}$ & $\begin{array}{l}K_{\mathrm{i}} \text { Human } \\
\operatorname{BPL}(\mu \mathrm{M})\end{array}$ & $\begin{array}{c}\text { anti-S. aureus } \\
\text { activity }^{a}\end{array}$ & $\begin{array}{l}\text { cytotox } \\
\text { HepG } 2^{b}\end{array}$ \\
\hline $12 \mathrm{~s}$ & $2-\mathrm{F}$ & $>10$ & $>16$ & - & $\mathrm{N} / \mathrm{D}$ \\
\hline $12 t$ & $3-F$ & $0.28 \pm 0.02$ & $>16$ & + & $>40$ \\
\hline $12 u$ & $4-F$ & $0.6 \pm 0.1$ & $>16$ & + & $>40$ \\
\hline $12 v$ & $2-\mathrm{Cl}$ & $>10$ & $>16$ & - & $\mathrm{N} / \mathrm{D}$ \\
\hline $12 w$ & $3-\mathrm{Cl}$ & $0.39 \pm 0.04$ & $>16$ & + & $>40$ \\
\hline $12 x$ & $4-\mathrm{Cl}$ & $1.1 \pm 0.07$ & $>16$ & + & $>40$ \\
\hline $12 y$ & 3,4-diF & $>10$ & $>16$ & - & $\mathrm{N} / \mathrm{D}$ \\
\hline
\end{tabular}

$a_{+}$, optical density of the culture reduced by $>40 \%$ of nontreated controls. -, compound did not inhibit bacterial growth. ${ }^{b}$ Compounds were assayed at $40 \mu \mathrm{g} / \mathrm{mL}$.

nm. Finally, selected compounds were assessed for potential toxicity using a cytotoxicity assay with cultured mammalian HepG2 cells (ATCC HB-8065). ${ }^{3}$

The initial series of alcohol analogues $12 \mathrm{a}-\mathbf{c}$ docked against $S a B P L$ were first assayed against the enzyme (Table 1 ) with the compound containing a $\mathrm{C} 4$ hydroxyl group (12c) showing modest activity $\left(K_{\mathrm{i}}=1.59 \mu \mathrm{M}\right)$. Interestingly, the $\mathrm{C} 2$ and $\mathrm{C} 3$ hydroxylated derivatives (12a and $\mathbf{1 2 b}$, respectively) were devoid of activity. It thus appears that the ribose pocket is sensitive to the position of the hydroxyl group and more so than predicted by the modeling. This observation is supported on analysis of the results for compounds containing other substituents, although there is little consistency regarding which position is most favored. Specifically, derivatives with a methoxyl group at $\mathrm{C} 2$ and $\mathrm{C} 3$ were both active $\left(\mathbf{1 2 d}, K_{\mathrm{i}}=\right.$ $\left.0.53 \mu \mathrm{M} ; 12 \mathrm{e}, K_{\mathrm{i}}=1.1 \mu \mathrm{M}\right)$, while the $\mathrm{C} 4$ analogue $(12 \mathrm{f})$ was inactive. For an amino substituent, $\mathrm{C} 2$ is active $\left(\mathbf{1 2 g}, K_{\mathrm{i}}=1.49\right.$ $\mu \mathrm{M})$, while both $\mathrm{C} 3(\mathbf{1 2 h})$ and C4 (12i) were inactive. Of the other derivatives initially tested, C3 methyl $\left(\mathbf{1 2 j}, K_{\mathrm{i}}=0.71 \mu \mathrm{M}\right)$, C4 carboxyl and tertiary butyl $\left(12 \mathrm{o}, K_{\mathrm{i}}=0.67 \mu \mathrm{M} ; 12 \mathrm{n}, K_{\mathrm{i}}=\right.$ $1.1 \mu \mathrm{M})$ were active. The 2-bromo and 4-iodo derivatives $12 \mathrm{p}$ and $12 \mathrm{r}$ showed good activity against $S$. aureus BPL $\left(K_{\mathrm{i}}=0.96\right.$ and $0.56 \mu \mathrm{M}$, respectively), and these compounds provided impetus for the expanded series of halogenated compounds shown in Table 2 and as discussed in detail below. A strongly electron withdrawing trifluoromethyl group at C3 and C4, resulted in compounds (121 and $\mathbf{1 2 m}$ ) that were devoid of activity against $\mathrm{S} a \mathrm{BPL}$. All of the biotin triazoles tested were inactive against human BPL when $100 \mu \mathrm{M}$ of compound was included in the assay medium. This is an important finding as it demonstrates that benzyl truncated triazoles retain the selectivity profile (i.e., active against $S$. aureus but not human $\mathrm{BPL})$ of the earlier and more complex triazoles. 3,15

The compounds shown in Table 1 were also assayed for antibacterial activity against $S$. aureus ATCC 49775. Compounds were designated as antibacterial if they reduced the optical density of the culture by $>40 \%$ relative to the nontreated controls (Figure 5). Of the 18 compounds assessed,

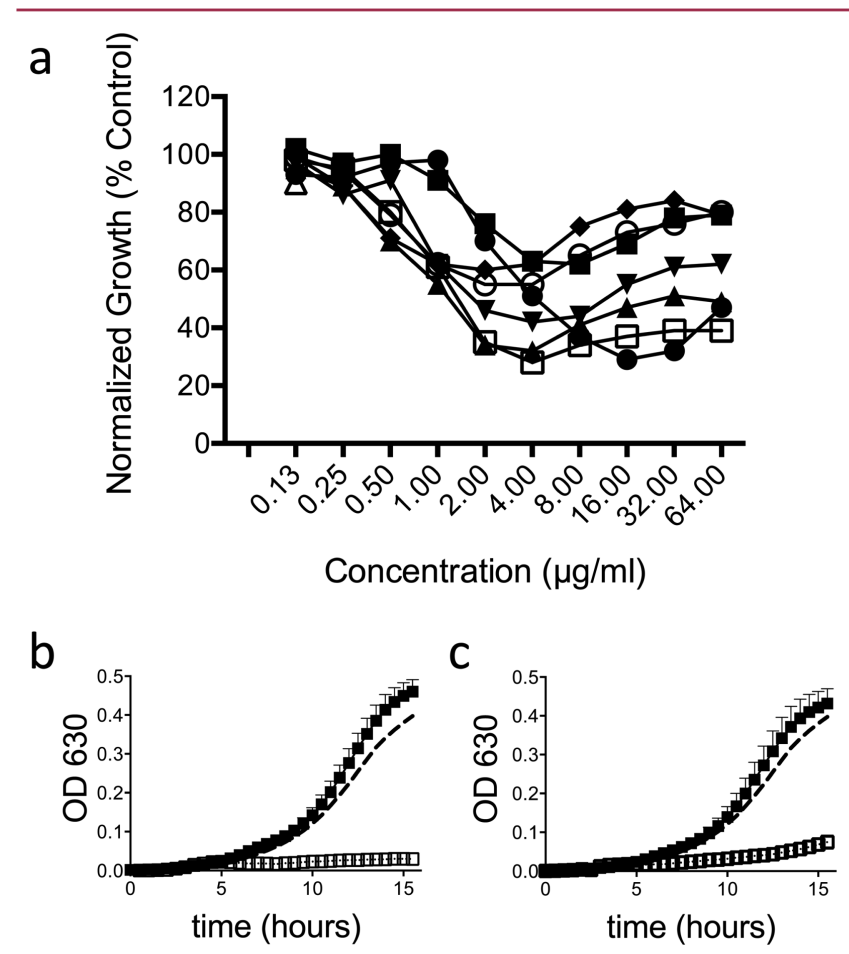

Figure 5. Inhibition of $S$. aureus growth in vitro. (a) Compounds $\mathbf{1 2 g}$ $(\square), 12 \mathrm{j}(\triangleleft), 12 \mathrm{p}(O), 12 \mathrm{r}(\triangle), 12 \mathrm{t}(\square), 12 \mathrm{u}(\bullet), 12 \mathrm{w}(\nabla)$, and $12 \mathrm{x}$ (A) were tested against $S$. aureus strain ATCC 49775. (b,c) Mechanism of action studies for $\mathbf{1 2 g}$ (b) and $\mathbf{1 2 t}$ (c). Growth curves for $S$. aureus RN4220 harboring the plasmid pCN51 (open boxes, negative control) or pCN51-BPL (solid boxes, for recombinant BPL overexpression) are shown. Growth media contained $16 \mu \mathrm{g} / \mathrm{mL}$ of compound, except, for no treatment controls (dashed line).

only five (those bearing amine, methyl, tertiary butyl, bromo, and iodo substituents, see $12 \mathrm{~g}, 12 \mathrm{j}, 12 \mathrm{n}, 12 \mathrm{p}$, and $12 \mathrm{r}$, respectively) were active in the whole cell assays. The fact that these compounds also inhibited SaBPL is consistent with a mechanism of antibacterial action being through the BPL target. It is possible that those BPL inhibitors devoid of whole

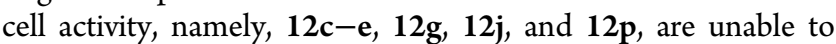
penetrate the bacterial membrane, a problem often encountered in antibacterial discovery. ${ }^{21}$

Of the extended halogenated series $(\mathbf{1 2 s}-\mathbf{x}$ in Table 2) four compounds displayed good activity against $S a B P L$, see 12t, $12 \mathrm{u}, 12 \mathrm{w}$, and $12 \mathrm{x}$ that had $K_{\mathrm{i}}$ values of $0.28,0.6,0.39$, and 1.1 $\mu \mathrm{M}$, respectively. A 3-halo substituent was most favored for 
activity as in $12 t$ and $12 w$. In these cases, the inhibition constants were approximately 2 - and 3-fold lower for the 3-vs 4- halogenated analogues, cf. $12 t / 12 u$ and $12 w / 12 x$. A 3-fluoro substituent $(\mathbf{1 2 t})$ provided the most potent compound in this series with a $K_{\mathrm{i}}=0.28 \mu \mathrm{M}$. The incorporation of a halogen at C2 removed all activity (see $12 \mathrm{~s}$ and $12 \mathrm{v}$ ) as did the introduction of a second fluoro substituent as in $12 y$. Again all active compounds in this series showed excellent selectivity for $S a \mathrm{BPL}$ over the human homologue. In addition, $\mathbf{1 2 t}, \mathbf{1 2 u}$, 12w, and 12x did not show cytotoxicity toward mammalian HepG2 cells at a single concentration of $40 \mu \mathrm{g} / \mathrm{mL}$.

Finally, to demonstrate that compounds inhibited protein biotinylation in vivo, antibacterial susceptibility assays were performed using a $S$. aureus strain engineered to overexpress the BPL target. Similar approaches to establish the mechanism of action have been employed on $M$. tuberculosis, ${ }^{10}$ but not previously for $S$. aureus. Bacteria were grown in media containing $16 \mu \mathrm{g} / \mathrm{mL}$ of either $12 \mathrm{~g}$ (series 1) or $12 \mathrm{t}$ (series 2) for $16 \mathrm{~h}$, with the optical density of the culture measured every $30 \mathrm{~min}$. Overexpression of the BPL target abolished the antibacterial activity of both compounds, as $S$. aureus grew at the same rate as nontreated controls (Figure 5b,c). Bacteria harboring the parent cloning vector $\mathrm{pCN}^{2} 1^{22}$ that did not express additional BPL, remained highly sensitive to both inhibitors and failed to grow in their presence. Together these data show that the mechanism of action of $\mathbf{1 2 g}$ (from series 1) and $12 t$ (series 2 ) is clearly via the inhibition of BPL.

The 1-benzyl substituted 1,2,3-triazoles reported here represent a new class of BPL inhibitors that lack the adenine group, or analogue thereof, found in all other isostere-based BPL inhibitors. These compounds have much reduced molecular weight and are relatively easy to prepare. Importantly, the biochemical and microbiological data provide a clear relationship between in vitro inhibition of BPL and anti$S$. aureus activity, with our most potent enzyme inhibitors generally providing our most promising antibacterials (see $\mathbf{1 2} \mathbf{j}$, $12 \mathrm{p}, 12 \mathrm{r}, 12 \mathrm{t}, 12 \mathrm{u}$, and $12 \mathrm{w}$ ). In antibiotic drug discovery, this is not always the case as a number of external factors contribute to bioactivity, such as cell permeability and susceptibility to efflux mechanisms and metabolic degradation.

The best lead compound in this new series (12t) with a 3fluoro substituted benzyl group, has a $K_{\mathrm{i}}$ of $280 \mathrm{nM}$ against $\mathrm{SaBPL}$ and demonstrated mechanism of antibacterial activity consistent with the inhibition of protein biotinylation. It is essentially nontoxic to mammalian HepG2 cells and is devoid of activity against human BPL. This compares to the extended 1,2,3-triazole 11 that has $K_{\mathrm{i}}$ of $90 \mathrm{nM}$ against SaBPL. This compound provides clear interactions with both the biotin and adenine pockets of $S a B P L$ and, like the new benzyl series, is essentially inactive against human BPL. ${ }^{3}$ Our initial SAR data on the new benzyl series provides confidence that further optimization of in vitro inhibition will lead to improved antibacterial activity. In silico docking supports a binding mechanism in which the benzyl group interacts with the ribose pocket of SaBPL. The compounds reported here provide important new scaffolds for further chemical modification and activity optimization, specifically to interact with the adjacent adenyl-binding site in the enzyme. Such studies are currently underway, particularly the inclusion of extended substituents on the benzyl group and also substitution at $\mathrm{C5}$ of the triazole.

\section{ASSOCIATED CONTENT}

\section{S Supporting Information}

The Supporting Information is available free of charge on the ACS Publications website at DOI: 10.1021/acsmedchemlett.6b00248.

Biological assays, synthetic procedures, and data for selected compounds (PDF)

\section{AUTHOR INFORMATION}

\section{Corresponding Author}

*Tel: +61 88 3135652. E-mail: andrew.abell@adelaide.edu.au.

Present Address

"School of Medical Sciences (Pharmacology) and Bosch Institute, The University of Sydney, Sydney, New South Wales 2006, Australia.

\section{Author Contributions}

The manuscript was written through contributions of all authors. Medicinal chemistry was performed by J.F., W.T., S.C., and A.D.A., biochemical assays were performed by A.S.P. and S.W.P., antibacterial susceptibility assays were performed by D.H. and A.H. under the guidance of S.W.P. and G.W.B., and cell culture assays were performed by A.H. and S.W.P.

\section{Funding}

This work was supported by the National Health and Medical Research Council of Australia (application APP1068885), the Centre for Molecular Pathology, University of Adelaide, and Adelaide Research and Innovation's Commercial Accelerator Scheme. We are grateful to the Wallace and Carthew families for their financial support of this work.

Notes

The authors declare no competing financial interest.

\section{ACKNOWLEDGMENTS}

We are grateful to the Institute for Photonics and Advanced Sensing (IPAS) for providing access to analytical HPLC and the National Health and Medical Research Council (NHMRC) and Australian Research Council (ARC) for funding. We also thank Dr. Beatriz Blanco Rodriguez for her critical comments on the manuscript.

\section{REFERENCES}

(1) Feng, J.; Paparella, A. S.; Booker, G. W.; Polyak, S. W.; Abell, A. D. Biotin Protein Ligase Is a Target for New Antibacterials. Antibiotics 2016, 5 (3), 26.

(2) Duckworth, B. P.; Nelson, K. M.; Aldrich, C. C. Adenylating enzymes in Mycobacterium tuberculosis as drug targets. Curr. Top. Med. Chem. 2012, 12 (7), 766.

(3) Soares da Costa, T. P.; Tieu, W.; Yap, M. Y.; Pendini, N. R.; Polyak, S. W.; Sejer Pedersen, D.; Morona, R.; Turnidge, J. D.; Wallace, J. C.; Wilce, M. C.; Booker, G. W.; Abell, A. D. Selective inhibition of biotin protein ligase from Staphylococcus aureus. J. Biol. Chem. 2012, 287 (21), 17823-32.

(4) Pendini, N. R.; Bailey, L. M.; Booker, G. W.; Wilce, M. C.; Wallace, J. C.; Polyak, S. W. Microbial biotin protein ligases aid in understanding holocarboxylase synthetase deficiency. Biochim. Biophys. Acta, Proteins Proteomics 2008, 1784 (7-8), 973-82.

(5) Polyak, S.; Abell, A.; Wilce, M.; Zhang, L.; Booker, G. Structure, function and selective inhibition of bacterial acetyl-coa carboxylase. Appl. Microbiol. Biotechnol. 2012, 93 (3), 983-992.

(6) Paparella, A. S.; Soares da Costa, T. P.; Yap, M. Y.; Tieu, W.; Wilce, M. C.; Booker, G. W.; Abell, A. D.; Polyak, S. W. Structure guided design of biotin protein ligase inhibitors for antibiotic discovery. Curr. Top. Med. Chem. 2014, 14 (1), 4-20. 
(7) Xu, Y.; Beckett, D. Kinetics of biotinyl-5'-adenylate synthesis catalyzed by the Escherichia coli repressor of biotin biosynthesis and the stability of the enzyme-product complex. Biochemistry 1994, 33 (23), 7354-7360.

(8) Brown, P. H.; Beckett, D. Use of binding enthalpy to drive an allosteric transition. Biochemistry 2005, 44 (8), 3112-3121.

(9) Bockman, M. R.; Kalinda, A. S.; Petrelli, R.; De la Mora-Rey, T.; Tiwari, D.; Liu, F.; Dawadi, S.; Nandakumar, M.; Rhee, K. Y.; Schnappinger, D. Targeting Mycobacterium tuberculosis Biotin Protein Ligase (MtBPL) with Nucleoside-Based Bisubstrate Adenylation Inhibitors. J. Med. Chem. 2015, 58 (18), 7349-7369.

(10) Duckworth, B. P.; Geders, T. W.; Tiwari, D.; Boshoff, H. I.; Sibbald, P. A.; Barry, C. E., 3rd; Schnappinger, D.; Finzel, B. C.; Aldrich, C. C. Bisubstrate adenylation inhibitors of biotin protein ligase from Mycobacterium tuberculosis. Chem. Biol. 2011, 18 (11), 1432-41.

(11) Brown, P. H.; Cronan, J. E.; Grøtli, M.; Beckett, D. The biotin repressor: modulation of allostery by corepressor analogs. J. Mol. Biol. 2004, 337 (4), 857-869.

(12) Tieu, W.; Polyak, S. W.; Paparella, A. S.; Yap, M. Y.; Soares da Costa, T. P.; Ng, B.; Wang, G.; Lumb, R.; Bell, J. M.; Turnidge, J. D.; Wilce, M. C.; Booker, G. W.; Abell, A. D. Improved Synthesis of Biotinol-5'-AMP: Implications for Antibacterial Discovery. ACS Med. Chem. Lett. 2015, 6 (2), 216-20.

(13) Sittiwong, W.; Cordonier, E. L.; Zempleni, J.; Dussault, P. H. beta-Keto and beta-hydroxyphosphonate analogs of biotin-5'-AMP are inhibitors of holocarboxylase synthetase. Bioorg. Med. Chem. Lett. 2014, 24 (24), 5568-71.

(14) Tieu, W.; Jarrad, A. M.; Paparella, A. S.; Keeling, K. A.; Soares da Costa, T. P.; Wallace, J. C.; Booker, G. W.; Polyak, S. W.; Abell, A. D. Heterocyclic acyl-phosphate bioisostere-based inhibitors of Staphylococcus aureus biotin protein ligase. Bioorg. Med. Chem. Lett. 2014, 24 (19), 4689-93.

(15) Tieu, W.; Soares da Costa, T. P.; Yap, M. Y.; Keeling, K. L.; Wilce, M. C. J.; Wallace, J. C.; Booker, G. W.; Polyak, S. W.; Abell, A. D. Optimising in situ click chemistry: the screening and identification of biotin protein ligase inhibitors. Chem. Sci. 2013, 4, 3533-3537.

(16) Pendini, N. R.; Yap, M. Y.; Polyak, S. W.; Cowieson, N. P.; Abell, A.; Booker, G. W.; Wallace, J. C.; Wilce, J. A.; Wilce, M. C. Structural characterization of Staphylococcus aureus biotin protein ligase and interaction partners: An antibiotic target. Protein Sci. 2013, 22 (6), $762-73$.

(17) Koziara, A. A Facile, One-Pot Conversion of Primary Alcohols into Amines. J. Chem. Res. (S) 1989, No. 9, 296-297.

(18) Soares da Costa, T. P.; Tieu, W.; Yap, M. Y.; Zvarec, O.; Bell, J. M.; Turnidge, J. D.; Wallace, J. C.; Booker, G. W.; Wilce, M. C.; Abell, A. D.; Polyak, S. W. Biotin analogues with antibacterial activity are potent inhibitors of biotin protein ligase. ACS Med. Chem. Lett. 2012, 3 (6), 509-14.

(19) Polyak, S. W.; Chapman-Smith, A.; Brautigan, P. J.; Wallace, J. C. Biotin Protein Ligase from Saccharomyces cerevisiae: The N-terminal domain is required for complete activity. J. Biol. Chem. 1999, 274 (46), 32847-32854.

(20) Cheng, Y.; Prusoff, W. H. Relationship between the inhibition constant $\left(K_{\mathrm{I}}\right)$ and the concentration of inhibitor which causes $50 \%$ inhibition (IC50) of an enzymatic reaction. Biochem. Pharmacol. 1973, 22 (23), 3099-108.

(21) Tommasi, R.; Brown, D. G.; Walkup, G. K.; Manchester, J. I.; Miller, A. A. ESKAPEing the labyrinth of antibacterial discovery. Nat. Rev. Drug Discovery 2015, 14 (8), 529-42.

(22) Charpentier, E.; Anton, A. I.; Barry, P.; Alfonso, B.; Fang, Y.; Novick, R. P. Novel cassette-based shuttle vector system for grampositive bacteria. Appl. Environ. Microbiol. 2004, 70 (10), 6076-6085. 